\title{
UN NUEVO REGISTRO DE CYPERUS PARA MÉXICO
}

\author{
Nelly Diego-Pérez \\ Facultad de Ciencias, UNAM \\ Ciudad Universitaria, Circuito Exterior \\ 04510 México, D.F. \\ Clara Hilda Ramos Álvarez \\ Y \\ Esteban Martínez \\ Instituto de Biología, UNAM \\ Ciudad Universitaria, Circuito Exterior \\ 04510 México, D.F.
}

\section{RESUMEN}

Se registra por primera vez para la flora de México a Cyperus gardneri Nees y se incluyen datos sobre su distribución.

Palabras clave: Cyperus, Cyperaceae, México.

\begin{abstract}
Cyperus gardneri Nees is reported for the first time for the flora of Mexico and some additional data on its distribution are included.

Key words: Cyperus, Cyperaceae, Mexico.

Durante el proceso de identificación del material colectado para el proyecto CONABIO-UNAM Colecta Botánica del Área Maya, Reserva de Calakmul, Campeche, llevado a cabo durante los años 1997-1998, se encontró Cyperus gardneri Nees, especie cuya distribución conocida abarcaba Guatemala, El Salvador, Brasil, Cuba, Argentina (Adams, 1994), Ecuador y Venezuela.

La especie se registró dos veces en la misma localidad (E. Martínez S. 30580-A y E. Martínez S. 31346), en un cuerpo de agua cuya profundidad varía según la época del año entre 0.50 y $1.50 \mathrm{~m}$, las coordenadas son $18^{\circ} 50^{\prime} 13^{\prime \prime} \mathrm{N}$ y $89^{\circ} 18^{\prime} 25^{\prime \prime} \mathrm{O}$, la altitud es de 175 m s.n.m. Esta pequeña laguna está rodeada de selva mediana subperennifolia
\end{abstract}


dominada por Bucida buceras L. ("pucté") y selva baja subcaducifolia con Haematoxylum campechianum L., Pachira aquatica Aublet, Talisia floresii Standley y Lonchocarpus xuul Lundell, entre otras. La especie más notable en el hábitat acuático es Typha domingensis Pers.

En la subsiguiente revisión de herbario se encontraron ejemplares provenientes del estado de Tabasco de A. Novelo y L. Ramos.

A continuación se presenta la descripción de la especie basada en las colectas realizadas en ambos estados.

Cyperus gardneri Nees in C. Martius, FI. Bras. 2(1): 34. 1842. Isotipo: Brasil, Gardner 1213. 1839 (BM). Fig. 1.

Hierbas viscosas, perennes, acuáticas, flotantes o arraigado-emergentes. Tallos de hasta $30 \mathrm{~cm}$ de alto. Hojas de $20-30 \mathrm{~cm}$ de largo y 2-3 mm de ancho, acuminadas, márgenes escabriúsculos. Brácteas desiguales, sobrepasando a la inflorescencia, de 4-15 cm de largo y 1.4-1.5 mm de ancho, foliiformes. Inflorescencia umbeliforme con 5 ó 6 rayos de 0.1-3 cm de largo, patentes. Espiguillas oblongas, con 6-9(10) flores, de 6-7 mm de largo y 2.4$2.5 \mathrm{~mm}$ de ancho, agrupadas en espigas globosas de 5-6 mm diámetro. Glumas carinadas, de 2-2.5 mm de largo y 2.3-2.5 mm de ancho, imbricadas, ampliamente ovadas, cuspidadomucronadas, cilioladas, brillantes, conspicuamente 7-10 nervadas, deciduas, con los lados de color pardo-rojizo pálido. Flores bisexuales, con 3 estambres, filamentos de 1.6-1.7 mm de largo, anteras de 0.4-0.5 mm de largo; estilo de 0.4-0.6 mm de largo. Aquenios pardos, de 1.3-1.5 mm largo y 0.7-1 mm de ancho, obovoides, trígonos, lados redondeados, la mitad superior y parte de los lados suberosa, brillante, estípite cuneado, celular, lustroso.

Ejemplares examinados: México. Campeche. Municipio Calakmul, a $3 \mathrm{~km}$ al $\mathrm{N}$ de Bel-ha, camino a Xcan-ha, E. Martínez S. 30580-A (MEXU); a $55 \mathrm{~km}$ al N de Xpujil, camino a Xcan-ha, E. Martínez S. 31346 (MEXU). Tabasco. Municipio Huimanguillo, Laguna del Rosario, posición NO, Ranchería Tres Bocas hacia la parte $\mathrm{N}$ del poblado, A. Novelo y $L$. Ramos 2051 (MEXU), 2389 (MEXU).

Hábitat: planta acuática, flotante o arraigada emergente, asociada a otras especies de Cyperaceae y Typhaceae. En Campeche se le encontró tanto flotante dentro de la aguada, formando parches con Salvinia sp., como arraigada emergente en el borde pantanoso. Floración y fructificación de diciembre a abril.

Kükenthal (1935-1936) coloca a esta especie dentro del subgénero Pycnostachys, en la sección Viscosi C. B. Clarke, equivalente a la sección Glutinosi Boeck., en virtud del tallo y las hojas viscosas, así como las flores con 3 estambres. Tucker (1994) la considera dentro del subgénero Cyperus, porque presenta las espiguillas agrupadas en espiga sobre un raquis, no en racimos capitados o digitados característicos del subgénero Pycnostachys.

Cyperus gardneri comparte con Cyperus elegans L. varias características, como el aspecto viscoso, las glumas ovadas, el aquenio obovoide, trígono, pero se distingue de esta especie por presentar en el aquenio tejido suberoso que cubre la mitad superior y parte de las superficies laterales, así como por las glumas cilioladas. 
Diego-Pérez et al.: Nuevo Registro de Cyperus para México
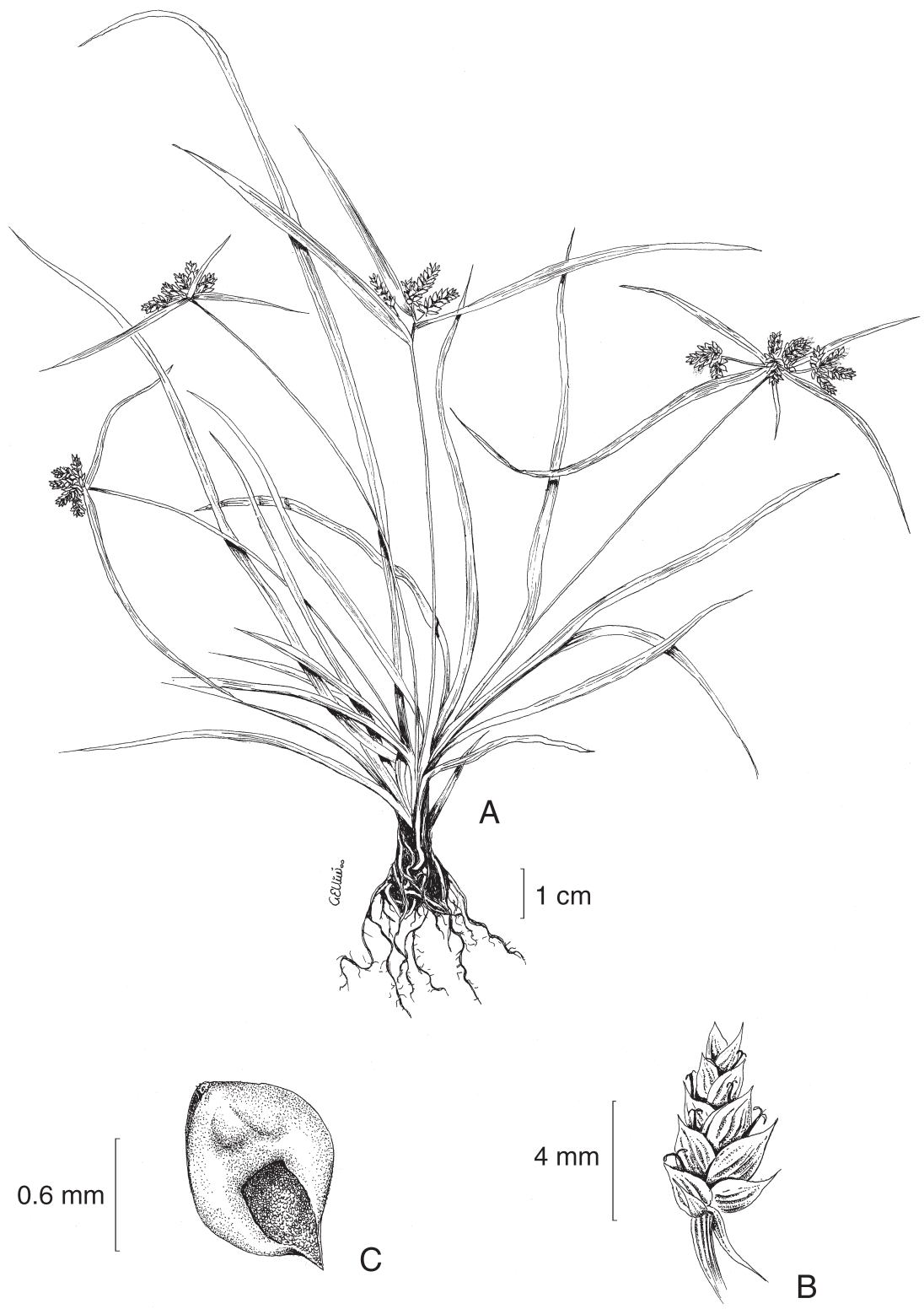

Fig. 1. Cyperus gardneri Nees, A. Planta completa; B. Espiguilla; C. Aquenio. Ilustrado por Ana Viniegra. 


\section{AGRADECIMIENTOS}

Se agradece al Dr. Mario Sousa S. el préstamo de los ejemplares y a la Biól. Ana Viniegra la ilustración de la planta.

\section{LITERATURA CITADA}

Adams, C. D. 1994. Cyperus. In: Davidse G., M. Sousa \& A. O. Chater (eds.). Flora Mesoamericana. Universidad Nacional Autónoma de México (Instituto de Biología), Missouri Botanical Garden \& The Natural History Museum (London). México, D.F. Vol. 6. pp. 423-440.

Kükenthal, G. 1935-1936. Cyperus (Cyperaceae: Scirpoideae). Das Pflanzenreich IV(20): 42-43, 163164.

Tucker, G. C. 1994. Revision of the Mexican species of Cyperus (Cyperaceae). Syst. Bot. Monogr. 43: 1-213. 